\title{
Women's opinions on the home management of early medical abortion in the UK
}

\author{
Patricia A Lohr, Josephine Wade, Laura Riley, Abigail Fitzgibbon, Ann Furedi
}

\begin{abstract}
Background and methodology This survey was undertaken to obtain the opinions of women in the UK about their home management of early medical abortion (EMA) with mifepristone and misoprostol. All eligible women undergoing EMA at any BPAS clinic during a 2-week period were invited to participate. Women were contacted by telephone 1 week after the EMA and a fiveitem structured questionnaire was administered. One open-ended question gave women the opportunity to freely comment. Demographics and responses were tabulated using descriptive statistics. Mulitivariable logistic regression was used to assess the influence of demographic characteristics on responses.
\end{abstract}

Results Of 249 enrolled participants, 162 were successfully surveyed (a $65 \%$ response rate). Most respondents $(86 \%)$ would rather go home to complete an EMA than remain in a clinical setting. The majority $(96 \%)$ found home management very or somewhat acceptable

\section{Introduction}

The UK's Abortion Act (1967) stipulates that any treatment for a termination of pregnancy must be carried out in a hospital or a place approved for this purpose by the Secretary of State. ${ }^{1}$ Although written at a time before early medical abortion (EMA) with mifepristone and misoprostol was available, current interpretation by the Department of Health is that both medications must be given in an authorised medical facility. This requires that women make two visits to a treatment unit for medication administration and a third visit to assess the outcome of treatment. In many hospital-based services in the UK, women undergo ward admission after misoprostol administration. ${ }^{2}$ However, most independent abortion providers and an increasing number of National Health Service (NHS) services discharge women after misoprostol administration to complete the process at home. Information is limited on the opinions of women in the UK regarding these practices or of home use of misoprostol, which is routine in many countries and has been shown to be safe and highly acceptable. ${ }^{3-7}$

\section{Methods}

Women fulfilling the requirements of the Abortion Act (1967), planning a medical abortion at $\leq 63$ days gestation with access to a telephone and ability to provide written valid consent were invited to participate. Adolescents under the age of 16 years were eligible if they were determined to be competent to give consent. Women were

BPAS (British Pregnancy Advisory Service), Stratford upon Avon, UK

Patricia A Lohr, MD, MPH, Medical Director

Josephine Wade, RN, PhD, Research Nurse

Laura Riley, Press and Public Policy Manager

Abigail Fitzgibbon, Press and Public Policy Officer

Ann Furedi, Chief Executive

Correspondence to: Dr Patricia Lohr, 20 Timothy's Bridge Road, Stratford Enterprise Park, Stratford upon Avon CV37 9BF, UK.

E-mail: patricia.lohr@bpas.org and $96 \%$ felt they could have obtained medical help easily if necessary. Most respondents (62\%) would prefer home use of misoprostol as opposed to returning to the clinic to obtain and use the medication. Women were less likely to prefer home management if they were Asian (OR 0.21 , $95 \% \mathrm{Cl} 0.05-0.87$ ) or had a gestational age $>49$ days (OR $0.26,95 \% \mathrm{Cl} 0.10-0.71)$.

Discussion and conclusions Home management of EMA is acceptable to most women in the UK who have experienced it and is, for many, preferable to a clinical setting. Consideration should be given to updating the interpretation of the UK's 1967 Abortion Act to allow home administration of misoprostol.

Keywords acceptability, home administration, medical abortion, mifepristone, misoprostol

J Fam Plann Reprod Health Care 2010; 36(1): 21-25

(Accepted 30 November 2009)

\section{Key message points}

- Most women surveyed report a preference for going home after misoprostol administration in order to complete an early medical abortion at home.

- Most women surveyed would prefer to self-administer misoprostol at home as opposed to returning to a clinic for administration.

- Asian women and those with a gestational age $>49$ days are less likely to prefer home management, however these findings should be interpreted cautiously given the small sample size of this study.

ineligible if they could not understand or communicate in English or had a special communication need impeding their ability to respond to questions administered over the telephone. An invitation to participate was made by a care provider after the client gave consent for treatment by EMA. Written valid consent was obtained to participate in the study.

All participants were provided with the standard regimen for EMA at BPAS which includes $200 \mathrm{mg}$ oral mifepristone followed 6-72 hours later by $800 \mu \mathrm{g}$ misoprostol placed vaginally at the treatment unit either by the women herself or a clinician, depending on the woman's preference. All women received either doxycyline or azithromycin antibiotic prophylaxis and were offered codeine phosphate tablets to take home for pain control. Women were discharged home after misoprostol administration to complete the medical abortion at home. Written and verbal information was provided on pain management, expected signs and symptoms of EMA, and indications for contacting the treatment unit or the BPAS Post Treatment Support Line, which provides advice and referral to emergency services, if needed, 24 hours a day.

At the time of enrolment, demographic characteristics and gestational age, as determined by abdominal or vaginal ultrasound examination, were recorded. One week following misoprostol administration, participants were contacted by telephone. Permission was requested at the 
Table 1 Demographics of survey respondents $(n=162)$

\begin{tabular}{lrr}
\hline Characteristic & & \\
\hline Age (years) [mean (range)] & & \\
Marital status [ $n(\%)]^{\mathrm{a}}$ & 28 & $(15-45)$ \\
Single & 66 & $(41)$ \\
Married & 44 & $(27)$ \\
Partnered & 43 & $(27)$ \\
Divorced/separated & 8 & $(5)$ \\
Ethnicity [ $n(\%)]^{\mathrm{b}}$ & 125 & $(78)$ \\
White & 19 & $(12)$ \\
Black/African & 12 & $(8)$ \\
Asian & 4 & $(3)$ \\
Other & 49 & $(7)$ \\
Gestational age (days) [mean (SD)]c & & \\
Gestational age category (days) [ $n(\%)]$ & 91 & $(58)$ \\
$\quad \leq 49$ & 42 & $(27)$ \\
$50-56$ & 25 & $(16)$ \\
$57-63$ & & \\
\hline
\end{tabular}

aOne non-respondent.

bTwo non-respondents.

cFour not recorded.

time of contact to conduct the survey. If the timing was inconvenient, the participant was able to request an alternative time and/or date. In order to preserve confidentiality, messages were not left for study participants who were unavailable at the time of the call. If a participant could not be reached after three attempts, no further attempts at contact were made. Participants were advised that they could withdraw from the study at any time and refuse to answer any questions to which they did not feel comfortable responding.

A five-item survey, developed for this study, was administered verbally and sought women's views on medical abortion at home and home use of misoprostol. One open-ended question allowed women to freely comment on their experience and opinions.

A convenience sample was sought from women requesting EMA at any BPAS treatment unit providing this service during 14 consecutive days. A total of 162 women were surveyed. With a response distribution of $50 \%$ and desired confidence level of $95 \%$, the margin of error with the achieved sample size is $7.8 \%$.

Descriptive statistics were tabulated and multivariable logistic regression was performed to assess the influence of demographic characteristics on responses using Stata $^{\mathrm{TM}}$ software version 9 (StataCorp LP, College Station, TX, USA).

\section{Ethical approval}

The project was given ethical approval by the BPAS Research and Ethics Committee.

\section{Results}

During a 2-week period in September 2008, 308 women were invited to participate, of whom 249 enrolled. The survey was successfully administered to 162 women (a response rate of $65 \%$ ). The demographics of the study sample are summarised in Table 1.

Most respondents $(86 \%)$ expressed a preference to go home to complete the abortion rather than remain in a clinical setting (Table 2). This was reflected in the acceptability of home management of EMA, with $96 \%$ of respondents stating that the experience was very or somewhat acceptable. In addition, $96 \%$ of respondents felt that they could have obtained medical help easily if needed while undergoing the abortion at home. When asked whether a requirement to stay in the clinic to complete the abortion would have altered their choice of abortion method, a quarter of the respondents reported that they would have chosen a surgical abortion instead. A majority (62\%) would prefer to take the misoprostol home and use it at home as opposed to returning to the clinic for administration.

The effect of demographic characteristics and gestational age on responses was assessed using multivariable logistic regression (Table 3). Neither age nor marital status significantly influenced responses to any of the questions. Women with a gestational age $>49$ days were less likely to report a preference for going home to complete an EMA [odds ratio (OR) 0.26, 95\% CI $0.10-0.71]$, however none of the other responses were significantly influenced by gestational age in this sample. Eight percent $(n=12)$ of the sample was of self-reported Asian ethnicity. Compared to other ethnic groups, Asian women were less likely to prefer home management (OR $0.21,95 \%$ CI $0.05-0.87)$, find home management very or somewhat acceptable (OR 0.13, 95\% CI 0.02, 0.87), report a preference for home use of misoprostol (OR $0.26,95 \%$ CI $0.07-0.93)$ or feel that they could get help easily if necessary (OR $0.13,95 \%$ CI $0.19-0.87$ ).

Table 2 Survey questions on home management of early medical abortion and responses $(n=162)$

\begin{tabular}{|c|c|c|c|}
\hline \multirow[t]{2}{*}{ Survey question } & \multicolumn{3}{|c|}{ Responses } \\
\hline & $n$ & $\%$ & $95 \% \mathrm{Cl}$ \\
\hline \multicolumn{4}{|c|}{ During your medical abortion at BPAS, you were able to go home to complete the abortion. } \\
\hline Go home to complete the abortion & 139 & 86 & $79-91$ \\
\hline Stay at the clinic until the abortion was completed & 23 & 14 & $9-21$ \\
\hline \multicolumn{4}{|l|}{ How acceptable was it for you to go home to have the abortion? } \\
\hline Somewhat acceptable & 27 & 17 & $11-23$ \\
\hline Somewhat unacceptable & 5 & 5 & $1-7$ \\
\hline Very unacceptable & 2 & 1 & $0.1-4$ \\
\hline \multirow{2}{*}{\multicolumn{4}{|c|}{$\begin{array}{l}\text { At BPAS, you had to return to the clinic to take the second medication. } \\
\text { If you were able to put the clock back on the treatment you had and were given the choice, } \\
\text { would you prefer to: }\end{array}$}} \\
\hline & & & \\
\hline Take the second medicine home with instructions on how to use it at home & 101 & 62 & $54-70$ \\
\hline Come back to the clinic and take the second medication at the clinic & 61 & 38 & $30-46$ \\
\hline \multicolumn{4}{|c|}{ If you had been required to stay at the clinic until the abortion had happened, would you have: } \\
\hline Chosen a surgical abortion instead & 39 & 25 & $18-32$ \\
\hline \multicolumn{4}{|l|}{ While you were having the abortion at home, did you feel: } \\
\hline That you could have obtained medical help easily if you needed it & 155 & 96 & $92-99$ \\
\hline That you could not have obtained medical help easily if you needed it & 6 & 4 & $1-8$ \\
\hline
\end{tabular}


Table 3 Univariable and multivariable logistic regressions of demographic characteristics on responses $(n=162)$

\begin{tabular}{|c|c|c|}
\hline Responses/demographic characteristics & $\begin{array}{l}\text { Unadjusted OR } \\
(95 \% \mathrm{Cl})\end{array}$ & $\begin{array}{l}\text { Adjusted ORa } \\
(95 \% \mathrm{Cl})\end{array}$ \\
\hline \multicolumn{3}{|l|}{ Preference to go home for EMA } \\
\hline Age $<28$ years & $0.69(0.28-1.74)$ & $0.56 \quad(0.22-1.54)$ \\
\hline Single/divorced & $1.39(0.56-3.41)$ & $1.48 \quad(0.57-3.85)$ \\
\hline Black/African & $0.49(0.14-1.68)$ & $0.47 \quad(0.13-1.71)$ \\
\hline Asian & $0.26(0.07-0.98)$ & $0.21 \quad(0.05-0.87)$ \\
\hline Gestational age $>49$ days & $0.33(0.13-0.84)$ & $0.26(0.10-0.71)$ \\
\hline \multicolumn{3}{|c|}{ Home management of EMA very/somewhat acceptable } \\
\hline Age $<28$ years & $1.88(0.41-8.67)$ & $1.58 \quad(0.32-7.90)$ \\
\hline Single/divorced & $0.63(0.14-2.89)$ & $0.65(0.13-3.23)$ \\
\hline Black/African & $0.58(0.06-5.44)$ & $0.60 \quad(0.06-5.95)$ \\
\hline Asian & $0.16(0.03-0.98)$ & $0.13(0.02-0.87)$ \\
\hline Gestational age $>49$ days & $0.28(0.05-1.40)$ & $0.26 \quad(0.04-1.47)$ \\
\hline \multicolumn{3}{|c|}{ Preference to take misoprostol home and use at home } \\
\hline Age $<28$ years & $0.66(0.34-1.27)$ & $0.60 \quad(0.30-1.20)$ \\
\hline Single/divorced & $1.00(0.53-1.90)$ & $1.08(0.56-2.10)$ \\
\hline Black/African & $0.74(0.28-1.96)$ & $0.77 \quad(0.29-2.08)$ \\
\hline Asian & $0.27(0.08-0.94)$ & $0.26 \quad(0.07-0.93)$ \\
\hline Gestational age $>49$ days & $0.94(0.49-1.80)$ & $0.81 \quad(0.41-1.59)$ \\
\hline \multicolumn{3}{|c|}{ If required to stay in clinic, would continue to choose medical abortion } \\
\hline Age $<28$ years & $1.67(0.81-3.46)$ & $1.77 \quad(0.83-3.75)$ \\
\hline Single/divorced & $1.28(0.61-2.66)$ & $1.30 \quad(0.61-2.77)$ \\
\hline Black/African & $0.91(0.30-2.74)$ & $0.81 \quad(0.26-2.51)$ \\
\hline Asian & $0.98(0.25-3.84)$ & $0.93 \quad(0.23-3.75)$ \\
\hline Gestational age $>49$ days & $0.64(0.31-1.35)$ & $0.68 \quad(0.32-1.44)$ \\
\hline \multicolumn{3}{|c|}{ Felt could get help easily during home management of EMA } \\
\hline Age $<28$ years & $1.41(0.27-7.19)$ & $1.62(0.28-8.89)$ \\
\hline Single/divorced & $1.76(0.31-9.87)$ & $1.82(0.31-10.69)$ \\
\hline Black/African & $0.43(0.04-4.38)$ & $0.38(0.04-4.03)$ \\
\hline Asian & $0.12(0.02-0.80)$ & $0.13(0.19-0.87)$ \\
\hline Gestational age $>49$ days & $1.47(0.26-8.28)$ & $1.39(0.23-8.34)$ \\
\hline
\end{tabular}

aCompared to age $\geq 28$ years, married/partnered, white/other, gestational age $\leq 49$ days.

EMA, early medical abortion.

An invitation to provide any further comment on their experience yielded responses from $110(68 \%)$ participants. Comments were coded for occurrence and codes converged into three main categories: medical abortion at home as a good experience; difficulties experienced on the journey home after misoprostol administration; and what helped make a medical abortion at home acceptable. For a lesser number of respondents other things stood out: home management as an individual choice; reasons for preferring to stay in the clinic; and unexpected concerns. Some respondent's comments fell into more than one category.

Forty-six (42\%) women talked about being able to manage the abortion at home as a good experience. Their remarks focused on the environment, "my own space", with home management of medical abortion most frequently described as "right", "comfortable", "relaxed", "convenient" and "private". As one participant stated: "It was not so mentally straining to be at home. I could have a friend with me to talk to and I could manage the mess in my own bathroom and not have to ask someone else to do it. I was a lot more comfortable than I would have been in a clinic". Twenty-five (23\%) women commented that good anticipatory guidance and caring nurses helped make home medical abortion acceptable.

Comments about the difficulty of the journey home after misoprostol administration were made by $23(21 \%)$ respondents. Many described returning to the clinic as inconvenient or were concerned about or experienced symptoms before reaching their destination. Rather than dissuade them from home management of EMA, this led to a support for home use of misoprostol. As one participant said: "I felt so anxious because I really felt that I had to hurry home. I would much rather have been able to do the second medicine in the comfort of my own home".

Five $(5 \%)$ women provided reasons why they would prefer to stay in the clinic, such as reassurance by a clinician that the abortion was proceeding as expected, and seven $(6 \%)$ were concerned about things that were unexpected, such as variability in the time to complete the abortion. Eight (7\%) women remarked that the decision to have home management should be an individual choice, surmising that characteristics such as age or support at home may be important issues for some women, but emphasising that the option should be available for everyone.

\section{Discussion}

Our findings indicate that women in the UK who are discharged after misoprostol administration to complete an EMA at home find this practice acceptable and preferable to a requirement that they remain in a clinical setting. This is similar to studies in the USA, Sweden, France, Vietnam and Mexico, which have all demonstrated that home medical abortion is highly acceptable. ${ }^{2-6}$ An important difference is that in those countries women may use the misoprostol at a place of their choosing, whereas in the UK women must return to the treatment unit for the misoprostol to be administered.

Due to the legal restriction on home use of misoprostol, the existing literature assessing the opinions of women in the UK on this practice is limited. An early study in Edinburgh $^{8}$ found that only $24 \%$ of 180 women who had experienced a medical abortion in a clinical setting would prefer to have the abortion at home. Similar results were reported by Hamoda et al. ${ }^{9}$ in their survey of 366 women who had undergone an EMA in four hospital-based services in England and Scotland. All participants remained in a clinical setting after the administration of misoprostol but were asked for their views on the hypothetical situation of having a medical abortion at home. Although $71 \%$ of respondents reported that there was nothing during their stay in hospital that they could not 
have managed on their own, only $36 \%$ would have opted for a home EMA. One small clinical trial in Aberdeen, Scotland explored the use of misoprostol at home ${ }^{10}$ and reported very different results. In this study, women up to 56 days' gestation were treated with $200 \mathrm{mg}$ oral mifepristone in a clinical setting followed by selfadministration of $600 \mu \mathrm{g}$ sublingual misoprostol 36-48 hours later at home. Of the 49 participants, 45 returned study questionnaires that asked about their experiences and opinions. Most $(96 \%, 37 / 44)$ of the respondents were very satisfied or satisfied with home EMA and 93\% (42/45 respondents) stated they would opt for medical abortion at home if necessary in future.

Our finding of a high acceptability of home management of EMA is similar to that of the latter study, perhaps because it reflects the opinions of women who have safely and satisfactorily experienced a medical abortion outside of a clinical setting. Most of our participants valued being at home, and were confident that they could access help easily if needed. A majority of our respondents would have also preferred administration of the misoprostol at home, citing the inconvenience of returning to the clinic or the concern raised by having the medication administered before a lengthy journey home. Nevertheless, the differences of opinion expressed in these studies emphasises the need to be cautious in interpretations of acceptability and in designing services. Women may be inclined to report a preference for the regimen they have received rather than one proposed as a theoretical alternative, particularly if the abortion was successful or occurred without incident. However, it is of note that nearly a quarter of the women in our study would have chosen a surgical abortion over a medical abortion had a requirement to stay in the clinic been imposed. Recognising that some women may have a strong preference for the setting of a medical abortion, retaining options for the location of treatment is reasonable provided there are adequate resources. In addition, for women who will undergo a medical abortion at home, it is important to manage their expectations and provide adequate support services such as a 24-hour telephone advice line.

In our study, women with a gestational age $>49$ days were less likely to prefer home management of EMA. The reason for this finding in our cohort is unclear; however, other studies have found that as gestational age advances, acceptability of medical abortion decreases. ${ }^{6,11}$ It has been suggested that this may be related to an increase in the amount of pain and amount and duration of bleeding experienced with a medical abortion as gestational age advances. We also found that women who self-identified as Asian were less likely than other ethnic groups to find the experience of home management of EMA acceptable or preferable. Ethnic variation in preferences for home medical abortion has been reported elsewhere. ${ }^{12}$ Winikoff et al. ${ }^{13}$ reported in their large study of the feasibility of EMA in the USA that Asian women were less likely than other women to feel comfortable self-administering misoprostol at home. This group was a mixture of East and South Asian women (B Winikoff, personal communication). As $8 \%$ of women having abortions in England and Wales in 2008 self-reported their ethnicity as Asian or Asian British, ${ }^{14}$ our findings deserve further investigation as they may reveal a need for special considerations in the management of medical abortion in some groups. However, they must be interpreted with caution given the small sample size of this study. When our sample was dichotomised by mean age of participants, there was no significant relationship. It should be noted that an evaluation of EMA pilot programmes in England published in 2008,15 which included community- and hospital-based settings as well as a BPAS clinic, found that whole young age was associated with less enthusiasm for going home after receipt of misoprostol or for home use. When regression models were built with our data to compare teen/non-teen, some did not converge because teen/non-teen was a perfect predictor of success. Age, as it relates to home misoprostol, is thus another area that deserves further exploration.

There are limitations of this study. This project was undertaken in anticipation of a parliamentary debate on modernising amendments to the current abortion law in the UK, which was to occur in October 2008. Thus, the gathering of data was time-sensitive, resulting in a small sample size. Additionally, the response rate (65\%) was lower than anticipated. To preserve confidentiality, the number on which we called participants appeared on their telephone as a 'withheld' number, we did not leave callback messages for participants, and we did not attempt to contact them more than three times. These measures may have decreased the number of women to whom the survey was administered. Finally, this study lacks a comparison group and was not randomised, therefore our ability to generalise the results is limited.

This study adds to the knowledge about women's opinions and preferences with regard to home management of EMA in the UK. As in other countries, home medical abortion was found to be highly acceptable, and a preference was expressed by most women for home use of misoprostol. In order to optimise the provision of EMA in the UK and further research into this area, consideration should be given to modernising regulations regarding the places where misoprostol may be administered for abortion.

\section{Acknowledgements}

The authors would like to thank the research participants, staff at participating BPAS units who undertook recruitment for this study, Beverly Elliston and Dominique Nixon who assisted in administration of the survey, and Adam Ward for technical support.

Statements on funding and competing interests

Funding None identified.

Competing interests BPAS is an independent provider of abortion services in the UK.

\section{References}

1 Abortion Act 1967 (c. 87). http://www.statutelaw.gov.uk [Accessed 24 July 2009].

2 Ingham R, Lee E. Evaluation of Early Medical Abortion (EMA) Pilot Sites. London, UK: Department of Health, 2008.

3 Fiala C, Winikoff B, Helström L, Hellborg M, GemzellDanielsson K. Acceptability of home-use of misoprostol in medical abortion. Contraception 2004; 70: 387-392.

4 Clark WH, Hassoun D, Gemzell-Danielsson K, Fiala C, Winikoff B. Home use of two doses of misoprostol after mifepristone for medical abortion: a pilot study in Sweden and France. Eur $J$ Contracept Reprod Health Care 2005; 10: 184-191.

5 Guengant JP, Bangou J, Elul B, Ellertson C. Mifepristonemisoprostol medical abortion: home administration of misoprostol in Guadeloupe. Contraception 1999; 60: 167-172.

6 Schaff EA, Fielding SL, Westhoff C, Ellertson C, Eisinger SH, Stadalius LS, et al. Vaginal misoprostol administered 1,2, or 3 days after mifepristone for early medical abortion: a randomized trial. JAMA 2000; 284: 1948-1953.

7 Ngoc NT, Nhan VQ, Blum J, Mai TT, Durocher JM, Winikoff B. Is home-based administration of prostaglandin safe and feasible for medical abortion? Results from a multisite study in Vietnam. Br J Obstet Gynaecol 2004; 111: 814-819.

8 Thong KJ, Dewar MH, Baird DT. What do women want during medical abortion? Contraception 1992; 46: 435-442.

9 Hamoda H, Critchley HOD, Paterson K, Guthrie K, Rodger M, Penney GC. The acceptability of home medical abortion to women in UK settings. Br J Obstet Gynaecol 2005; 112: 781-785. 
10 Hamoda H, Ashok PW, Flett GMM, Templeton A. Home selfadministration of misoprostol for medical abortion up to 56 days' gestation. J Fam Plann Reprod Health Care 2005; 31: 189-192.

11 Teal SB, Dempsey-Fanning A, Westhoff C. Predictors of acceptability of medication abortion. Contraception 2007; 75: 224-229.

12 Ho PC. Women's perceptions on medical abortion. Contraception 2006; 74: 11-15.

13 Winikoff B, Ellertson C, Elul B, Sivin I. Acceptability and feasibility of early pregnancy termination by mifepristonemisoprostol. Results of a large multicenter trial in the United States. Mifepristone Clinical Trials Group. Arch Fam Med 1998; 7: 360-366.

14 Department of Health. Abortion Statistics, England and Wales: 2008 (Statistical Bulletin 2009/1). London, UK: Department of Health, 2009.

15 Department of Health. Evaluation of Early Medical Abortion (EMA) Pilot Sites: Final Report. London, UK: Department of Health, 2008.

\section{How not to make a pig's ear of swine flu immunisation}

\section{Polly Clinic}

The swine flu pandemic may have some unforeseen consequences. Due to the major vaccination programme and also the possible burden of increased consultations on GP surgeries, health professionals in other branches of medicine have been approached to help.

It is an undeniable truth that patients always attend with more than one problem when they see their GP. To meet patient needs, here are some helpful hints and tips for specialist family planning health professionals, using their skill and experience in their field, while at the same time focusing on the green agenda of reduce, reuse and recycle.

Paronychia may be easily treated using the needle of the Depo-Provera ${ }^{\circledR}$ syringe. The syringe can then be recycled for ear syringing.

Physiotherapy referrals can be avoided by prescribing diaphragms - the spring makes an excellent hand exercise device, and chasing a diaphragm around the room when it springs out of the hand gives useful exercise for the whole body. If it should also be needed for its original purpose, the position for insertion gives added benefits for flexibility of the hips. Out-of-date contraceptive pill packets can be recycled by advising patients with finger stiffness to pop out the pills one at a time, then when they jump out and fall on the floor under the chest of drawers, kneel down, bend almost prone and pick them up using the thumb and each other finger in turn.

Finger injuries and sprains can be splinted with implants, and condoms can be helpful as a substitute for finger cots. Remember to advise the use of condoms for Mr Blue who now has a twinkle in his eye since meeting the widow Mrs Puffer in the Breathe Easy Class - and she will need some lubricants as well.

Vigorous massaging of lubricants will also benefit patients with arthritis - patients may present with early morning stiffness of various types.

The convenient strings on intrauterine devices (IUDs)

J Fam Plann Reprod Health Care 2010; 36(1): 25

Multitasker Surgery, Speedington, UK

Polly Clinic, DFSRH, General Practitioner can be used for ligation of skin tags - advise the patient that the weight of the coil hanging down will encourage separation as well as providing an interesting topic of conversation down the pub.

For stress-related problems, simply prescribe Persona $^{\mathrm{TM}}$ and advise intercourse on all green days. This method can equally be used for anger management, exercise referrals, irritable bowel syndrome, tension headaches, and so on. Using Persona to identify premenstrual days can benefit husbands and partners so that they can be out of the house at the correct time of the month.

Used Evra ${ }^{\circledR}$ patches can be used as waterproof dressings, although you may need to add a little extra adhesion round the edges.

If you have any old caps or diaphragms in your room, these can be reused as nipple shields to prevent jogger's nipple, or as breast shields after delivery for those pregnant patients who will be breastfeeding later.

The contraceptive sponge has a new lease of life for patients with hyperhidrosis, and provides extra protection for urinary incontinence when used together with a diaphragm.

Femidoms - we cannot think of any uses for these. Answers on a postcard please.

Patients requesting referral for breast augmentation can take combined oral contraceptives as a trial to see how they like their new body shape.

Acne can be treated using Dianette ${ }^{\circledR}$ (and yes, you can prescribe this in GP surgeries!).

A speculum can be used to keep the mouth open while examining the throat - this is especially useful in small children. Like dentists, we are used to wearing gloves, so wear them all the time for any contact with patients to avoid infecting yourself, using hand washing and/or alcohol gels between each patient to avoid crossinfection. Remember - your role is health prevention ... or should that be illness prevention?

A final piece of advice - leave a copy of The Joy of Sex in the waiting room to supplement the usual tatty magazines and health promotion leaflets. Not only will patients be happy to wait half an hour to see you, they may decide they don't need to see you after all.

\section{FACULTY AWARDS}

The Faculty of Sexual and Reproductive Healthcare has available a number of annual awards for which applications are invited from Faculty members/non-members. Details of the individual awards, and application forms and/or guidelines on how to apply and any eligibility criteria, may be found on the Faculty website at www.fsrh.org (Scholarship \& Awards). 